\title{
Causal Attribution of Students to their Academic Achievement
}

\author{
Habtamu Genet ${ }^{1}$ \\ ${ }^{1}$ University of Gondar, College of Social Sciences and Humanities, Gondar Ethiopian
}

\begin{abstract}
This study examined causal attributions by college-age students regarding their academic achievement. A descriptive survey design was employed to measure the existing attribution level of the students. Simple random sampling method was used to select sample departments from each college, and representative samples were selected from each department based on academic rank. The total participants involved in this study were 104 second year students at Mizan-Tepi University in Ethiopia. They completed a multiattributional causality scale with items related to ability, effort, context and luck dimensions. Means, independent sample t-tests, and one-way analysis of variance (ANOVA) were used for analysis. The results showed that the majority of students attributed their academic achievement to internal factors. Academic success was attributed to internal factors while academic failure was attributed to external factors. Moreover, high- and medium-achievers tended to attribute their academic achievement to effort and ability while students with low achievement were more likely to assign the causes of academic success and failure to luck. Sex differences revealed that males tended to attribute their academic achievement to ability, whereas for females there was no significant difference in their attribution to effort, context or luck.
\end{abstract}

Keywords: Attribution, Academic Achievement, Internal Attribution, External Attribution, Causal attribution

\section{Introduction}

Human beings are constantly searching for the cause behavior. According to Heider (1958), people broadly attribute the causes of behavior either to internal or external factors. An internal attribution is causes that are associated with the person's innate characteristics such as personality traits, moods, attitudes, abilities or efforts. And an external attribution on the other hand, is the causes that are external to the person, such as the actions of others, environmental situation or luck.

Attribution theory explains academic success and failure in terms of three sets of characteristics. First, the cause of the success and failure may be internal or external. That is, people may succeed or fail because of factors that they believe have their origin within them or because of factors that originate in their environment. Second, the cause of the success and failure may be either stable or unstable. If the cause is stable, then the outcome is likely to be the same if students perform the same behavior on another occasion. If it is unstable, the outcome is likely to be different on another occasion. Third, the cause of the success and failure may be either controllable or uncontrollable. A controllable factor is one which people believe they can alter if they wish to do so. An uncontrollable factor is one that people do not believe they can easily alter (Wiener, 1985).

Ability, effort, task difficulty and luck are the four attributional styles to which people ascribe their successes and failures Hashemi. R. and Zabihi. R. (2011). The cause of events can be internal/external, stable/unstable, and controllable/uncontrollable. Locus is whether the cause of events is perceived as internal or external. While ability and effort are internal attributions, luck and task difficulty are external factors. The stability dimension is the extent to which the cause of an event is fixed and stable, or unstable, over time. Ability, for instance, is regarded as stable; effort, on the other hand, is considered to be an unstable dimension. Finally, control examines how much control an individual has over a cause.

Asonibare B. (1986) found that students attribution do not differ by sex. Furthermore, a study by Ian, Wenfan; Gaier, Eugene L. (1991) depicted that male and female students did not significantly differ in the ratings of the attributions for achievement. They both believed that effort was the most important factor for academic achievement, followed by ability, task and luck.

On the other hand, both male students and female students tend to attribute their success to their high ability more than they attributed their failure to their lack of ability (Eugene, 1991). On the average, both males and females tend to attribute their success to their great effort equally as they attributed their failure to lack of effort (ibd). On average, both males and females attribute success to good luck equally as they attributed their failure to bad luck (ibd).

The attributions for achievement outcomes that have received the most empirical attention include ability (internal, stable), effort (internal, unstable), task difficulty (external, stable), and luck (external, unstable) (Weiner, 1985). Arkin and Maruyama (1979) also found that, people show a self-enhancing bias in attributions, participants attribute greater responsibility to ability and effort in explaining success than failures, whereas failure participants attribute greater responsibility to external factor such as task difficulty than success participants.

The recent explorations of achievement motivation will investigate factors that appear to determine and influence the academic achievement of university students. Typically, these causal factors are conceptualized as ability, effort, context and luck (Weiner, 2008). When students do better in their academic achievement, they attribute to internal factors. And when they do poorly, they attribute to externalize factors. For Weiner (2008), 


\section{International Journal of Science and Research (IJSR) \\ ISSN (Online): 2319-7064}

Index Copernicus Value (2013): 6.14 | Impact Factor (2014): 5.611

attribution inquiry is still strong enough to attract attention of the researchers as students still react when they hear about their grades in a classroom test. Therefore, the present study fills the gap existed the way students attribute the causes of academic achievement.

1. Do the students differently attribute academic success and failure depending on whether they are internally or externally oriented?

2. What are the differences in the ways the students' claim responsibility for academic success or failure depending on their form at school?

3. How do boys differ from girls in the ways they attribute academic success and failure?

\section{Methods}

\subsection{Design}

The research method employed is determined by nature of research topic (Creswell 2003). Therefore, descriptive survey method was employed for its appropriateness to get broad descriptions of quantitative information and to identify attributinional styles of students in academic achievement.

\subsection{Sample and Sampling Procedures}

The participants of the present study were Mizan-Tepi University students in Ethiopia, who are attending the new educational system, modularization.

To ensure the representativeness of the sample size and equal chance of the population to be selected, a probability sampling method was employed. Therefore, simple random sampling i.e. lottery method was utilized in order to differentiate students based on department in each college level. Finally, representative samples were selected from each department based on their academic rank.

\subsection{Instrument and Procedure}

When conducting this study Multidimensional Multiattributional Causality Scale developed by Herbert M. Lefcourt (1981) was adapted and used. The scale consists of items concerning experiences of academic failure and experiences of academic success. To test the appropriateness of the instrument to the target sample, the scale was piloted and the Cronbach Coefficient Alpha was calculated and found to be for luck (0.813), context (0.796), effort (0.727) and ability (0.633) respectively.

\subsection{Method of Data Analysis}

Different data analysis techniques were employed for this study. Mean was employed to analyze the level of causal attribution based on internally or externally oriented situations. T-test was utilized in order to analyze the significance difference between male and female in the way they attribute to academic success and failure. And one way ANOVA was used to analyze the significance differences between high, medium, and low achievers in attibutional dimensions.

\section{Results}

The aim of this section is to present the key findings in the context of the original objectives of this research. Therefore, all the data gathered through questionnaires were presented and analyzed in accordance with the basic research questions.

Table 1: Biographical Information of Respondents

\begin{tabular}{|c|c|c|c|}
\hline Variables & & Frequency & Percent \\
\hline Sex & Male & 59 & 56.7 \\
\hline & Female & 45 & 43.3 \\
\hline $\begin{array}{c}\text { Academic } \\
\text { achievement }\end{array}$ & Total & 104 & 100 \\
\hline & Medium & 33 & 31.7 \\
\hline & High & 36 & 33.7 \\
\hline & Total & 104 & 34.6 \\
\hline
\end{tabular}

Table 1 demonstrates the biographical information of the respondents with regard to distribution of gender and forms of achievement. A total of 104 students were identified and participated in this study. From these, 59(56.7\%) were males and 45(43.3\%) were females. With respect to their forms of academic achievement, 36(34.6\%) of the respondents were high achievers, 35(33.7\%) were medium achievers and $33(31.7 \%)$ of them were low achievers.

Table 2: Mean Academic Achievement Scores of Students with Attributional Dimensions

\begin{tabular}{|c|c|c|c|}
\hline \multirow{2}{*}{$\begin{array}{c}\text { Attributional } \\
\text { Dimensions }\end{array}$} & \multicolumn{3}{|c|}{ Academic Achievement } \\
\cline { 2 - 4 } & $\mathrm{N}$ & $\mathrm{M}$ & $\mathrm{SD}$ \\
\hline Internal & 104 & 42.3173 & 7.08104 \\
\hline External & 102 & 32.6863 & 7.96152 \\
\hline
\end{tabular}

As Table 2 depicts, the difference between means is statistically significant in the attribution dimension. Thus, the majority of the respondents $42.32( \pm 7.08 \mathrm{SD})$ tend to attribute the cause of academic achievement to internal factors (ability \& effort) while the remaining $32.69( \pm 7.96 \mathrm{SD})$ to external factors (context \& luck).

Table 3: Students' Claim Responsibility for academic Success and Failure

\begin{tabular}{|c|c|c|c|c|c|c|c|c|}
\hline \multirow{3}{*}{$\begin{array}{c}\text { Varia } \\
\text { bles }\end{array}$} & \multicolumn{6}{|c|}{ Forms of Achievement } & \multirow{4}{*}{$\begin{array}{c}F \\
365\end{array}$} & \multirow[b]{3}{*}{ Sig } \\
\hline & \multicolumn{2}{|c|}{ Low } & \multicolumn{2}{|c|}{ Medium } & \multicolumn{2}{|c|}{ High } & & \\
\hline & $\mathrm{M}$ & $\mathrm{SD}$ & $\mathrm{M}$ & SD & $\mathrm{M}$ & SD & & \\
\hline Abilit & 19.7 & 4.40 & 20.3 & 2.9 & 22.0 & 3.28 & & م \\
\hline $\mathrm{y}$ & 576 & 19 & 714 & 51 & 0 & 6 & $8 *$ & $\begin{array}{l}0.0 \\
29\end{array}$ \\
\hline $\begin{array}{c}\text { Conte } \\
\text { xt }\end{array}$ & 17.2 & $\begin{array}{c}2.48 \\
3\end{array}$ & $\begin{array}{c}17.5 \\
7\end{array}$ & $\begin{array}{c}2.9 \\
7\end{array}$ & $\begin{array}{c}16.5 \\
1\end{array}$ & 3.89 & .955 & $\begin{array}{l}0.3 \\
89\end{array}$ \\
\hline Effort & $\begin{array}{l}19.3 \\
939\end{array}$ & $\begin{array}{c}4.44 \\
3\end{array}$ & $\begin{array}{l}22.2 \\
857\end{array}$ & $\begin{array}{c}4.1 \\
7\end{array}$ & $\begin{array}{c}23.5 \\
429\end{array}$ & $\begin{array}{c}3.95 \\
8\end{array}$ & $\begin{array}{l}8.69 \\
3 * *\end{array}$ & $\begin{array}{c}0.0 \\
00\end{array}$ \\
\hline Luck & $\begin{array}{c}16.8 \\
38\end{array}$ & 5.82 & $\begin{array}{l}18.3 \\
938\end{array}$ & $\begin{array}{c}4.0 \\
3\end{array}$ & $\begin{array}{l}15.1 \\
143\end{array}$ & $\begin{array}{c}15.4 \\
27\end{array}$ & $\begin{array}{c}3.46 \\
3 *\end{array}$ & $\begin{array}{c}0.0 \\
35\end{array}$ \\
\hline
\end{tabular}

$* \mathrm{P}<0.05, * * \mathrm{P}<.001$

As it is evident in table 3 , the difference between mean was statistically significant among the forms of achievement for effort $\mathrm{F}(2,100)=8.693, \mathrm{P}=0.05$; ability $\mathrm{F}(2,101)=3.658, \mathrm{P}=0.05$; and luck $\mathrm{F}(2,96)=3.463, \mathrm{P}=0.05$ respectively. Furthermore, on average students with high 


\section{International Journal of Science and Research (IJSR) \\ ISSN (Online): 2319-7064 \\ Index Copernicus Value (2013): 6.14 | Impact Factor (2014): 5.611}

achievers $(\mathrm{M}=22.00)$, medium achievers $(\mathrm{M}=20.3714)$ and low achievers $(M=19.7576)$ tend to attribute academic achievement to ability respectively. In effort wise, high achievers $(M=23.54)$, medium achievers $(M=22.29)$ and low achievers $(M=19.39)$ tend to attribute the causes of academic achievement toward effort separately. With regard to luck, medium achievers $(M=18.39)$, low achiever $(M=16.84)$ and high achievers $(M=15.11)$ attributed for by luck respectively. However, there was no statistically significant difference observed among high achievers, medium achievers and low achievers in their attribution of academic achievement with regard to context.

Table 4: Attributions for Academic Achievement by Gender

\begin{tabular}{|c|c|c|c|c|c|c|}
\hline Variable & Sex & $N$ & Mean & $S D$ & $t$ & $P$ \\
\hline \multirow{2}{*}{ Ability } & Male & 59 & 21.5294 & 2.97319 & \multirow{2}{*}{2.546} & \multirow{2}{*}{$0.012 *$} \\
\hline & Female & 45 & 19.7111 & 4.24062 & & \\
\hline \multirow{2}{*}{ Effort } & Male & 58 & 22.3621 & 4.20817 & \multirow{2}{*}{1.483} & \multirow{2}{*}{0.141} \\
\hline & Female & 45 & 21.0444 & 4.79088 & & \\
\hline \multirow{2}{*}{ Context } & Male & 54 & 16.6667 & 3.30237 & \multirow{2}{*}{$\begin{array}{c}- \\
1.510\end{array}$} & \multirow{2}{*}{0.134} \\
\hline & Female & 44 & 17.6363 & 2.9817 & & \\
\hline \multirow{2}{*}{ Luck } & Male & 55 & 16.3091 & 4.913 & \multirow{2}{*}{-.952} & \multirow{2}{*}{0.357} \\
\hline & Female & 44 & 17.2955 & 5.692 & & \\
\hline
\end{tabular}

$* \mathrm{P}<0.05$

Table 3 reveals that the mean of males 21.53( $\pm 2.97 \mathrm{SD})$ and females 19.71( $\pm 4.24 S D)$ were attributed for by ability respectively. Therefore, there is a statistically significant mean difference between males and females with regard to their attribution of academic achievement to ability $(\mathrm{t}=0.012, \mathrm{P}<0.05)$. However, there is no statistically significant difference between the two genders in the attribution of academic achievement by effort $(\mathrm{t}=1.48$, $\mathrm{P}>0.05)$, context $(\mathrm{t}=-1.51, \mathrm{P}>0.05)$ and luck $(\mathrm{t}=-0.95$, $\mathrm{P}>0.05)$.

\section{Discussion}

The results of the present study showed that the majority of students tend to attribute the causes of academic achievement toward internally oriented situation. Whatever the academic achievement is, success and failure, students tend to attribute this phenomenon to ability and effort. This result is confirmed with Eugene L. (1991) found out that effort and ability were the most important factor for academic achievement, followed by task and luck.

Attributions for Academic Achievement as success and failure at school, students with high achievers tend to attribute the causes of academic achievement to effort and ability while students with low achievers assign the causes of academic success and failure to luck. This finding is opposite to Morris (2013) depicted that, the attributions students gave for academic events did not predict performance.

Save for sex, males and females differ significantly on dimension of ability as the t-value 0.012 was found to be significant. The observation of mean scores revealed that males and females had different attribution to ability (21.53, 19.71 respectively). Male student's beliefs in their ability more than females did. This result is contrary to a study by Eugene (1991) found out that on average both male students and female students tend to attribute academic success to their high ability more than they attributed failure to their lack of ability.

However, comparison of t-value of males and females (Table 3) on effort, context and luck were found to be nonsignificant. The males and females were having almost similar attribution toward academic achievement. This finding is consistent with Eugene (1991) found out that both male students and female students tend to assign the causes of academic achievement to effort, context and luck in similar way. When they are successful in their academic achievement, they attributed to their great effort and good luck while when they are failing to be successful, they assigned to lack of effort and bad luck.

\section{References}

[1] Asonibare, J.B. (1982). Traditional beliefs and the attribution of success and failure among the Nigerian High School Students. Unpublished Doctoral Dissertation. University of Pittsburgh.

[2] Arkin, M. Maruyama, Geoffery, M. (). Attribution, affect, and college exam performance. Journal of educational psychology, Vol71 (1).85-93. http://dx.doi.org/10.1http://www.aweonline.org.037/0 022-0663.71.1.85.

[3] Creswell, W. (2003). Research Design: Qualitative and Quantitative Approach and Mixed Method Approach. London: SAGE Publication.

[4] Heider, F. (1958).Psychology of Interpersonal Relations. New York: Wiley. http://dx.doi.org/10.1037/10628-000

[5] Morris,M. (2013). The impact of attribution on academic performance: a test of the formulated learned helplessness model. Social sciences directory. Vol.2 No.2, 3-5. http://dx.doi.org/10.7563/ssd-02-0201.

[6] Weiner, B. (1985). An Attributional theory of achievement motivation and emotion. Psychological Review, 92(4), 548-573. http://dx.doi.org/10.1037/0033-295X.92.4.548

[7] Weiner, B. (2008). Reflection on the history of attribution theory and research: people, personalities, publication and problems. Journal of social psychology $\quad$ vol39 (3), 151-156. http://dx.doi.org/10.1027/1864-9335.39.3.151.

[8] Lefcourt, H. M. (1981). The construction and development of the MultidimensionalMultiattributional Causality Scales.

[9] H. M. Lefcourt (1981.). Research with the Locus of Control Construct. London Academic Press.

[10] Weiner, B. (2006). Social motivation, justice, and the moral emotions: An attributional approach. Mahwah, NJ: Lawrence Erlbaum Associates.

[11]Weiner, B. (2008). Reflections on the history of attribution theory and research: People, Personalities, publications and problems. Journal of Social Psychology, Vol39 (3), 151-156. Retrieved from: http://dx.doi.org/10.1027/1864-9335.39.3.151. 


\section{International Journal of Science and Research (IJSR) \\ ISSN (Online): 2319-7064}

Index Copernicus Value (2013): 6.14 | Impact Factor (2014): 5.611

[12] Assessing Women in Engineering (AWE) Project 2005. Attribution Theory. AWE Research Overviews. Retrieved $>$ date $<$ from http://www.aweonline.org.

\section{Author Profile}

Habtamu Genet received his BA degree from Jimma University and his MA degree from Addis Ababa University in 2007 and 2011 respectively. He employed in Mizan-Tepi University from 2007-2014 as a range of Graduate assistant I to lecturer. From the year September 11, 2014 to date he served as a lecturer at university of Gondar. In addition to the teaching learning process, he is doing research in education, organizational behavior and psychosocial issues. Besides to this, he is engaged in community service. 